Çukurova Üniversitesi Mühendislik Fakültesi Dergisi, 36(2), ss. 283-296, Haziran 2021

Cukurova University Journal of the Faculty of Engineering, 36(2), pp. 283-296, June 2021

\title{
Manyetik Nanopartiküllerin Anaerobik Çürütücüde Biyogaz Üretimi Üzerine Etkileri
}

\author{
Özlem DEMIIR ${ }^{* 1}$, Nurcan ATEŞ² \\ ${ }^{1}$ Harran Üniversitesi, Mühendislik Fakültesi, Çevre Mühendisliği Bölümü, Şanlıurfa \\ ${ }^{2}$ Harran Üniversitesi, Fen Bilimleri Enstitüsü, Çevre Mühendisliği Anabilim Dall, Şanlıurfa
}

Geliş tarihi: 05.03.2021 Kabul tarihi: 30.06 .2021

$\ddot{\mathbf{O z}}$

Atıksu arıtma tesislerinde üretilen çamurun stabilizasyonu ve yenilenebilir enerji üretmek için yaygın olarak kullanılan işlemlerden biri olan anaerobik çürütme, birçok mikroorganizma grubu tarafından gerçekleştirilen bir işlemdir. Günümüzde, bilimsel araştırmalar için yeni bir alan olan nanoteknolojideki gelişmeler, nanopartiküllerin birçok alanda kullanılmasını sağlamıştır. Nanopartikülleri anaerobik çürütücülerdeki metan üretimi ve stabilizasyon üzerine etkileri son yıllarda dikkat çeken bir konu haline gelmiştir. En bilinen ve yaygın olarak kullanılan nanopartüküllerden biri $\mathrm{Fe}_{3} \mathrm{O}_{4}$ 'tir. $\mathrm{Bu}$ çalışmada, nanopartikül uygulamaları hakkında bilgi verilerek ve manyetik nanopartiküllerin, özellikle de $\mathrm{Fe}_{3} \mathrm{O}_{4}$ manyetik nanopartiküllerinin anaerobik çürütücüde biyogaz üretimi üzerine etkileri ile araştırılmıştır. Ayrıca, laboratuvar ortamında, birlikte çökeltme yöntemi ile $\mathrm{Fe}_{3} \mathrm{O}_{4}$ manyetik nanopartikülü sentezlenmiş ve manyetik özellikleri değerlendirilmiştir. $\mathrm{Fe}_{3} \mathrm{O}_{4}$ sentezlendikten sonra farklı konsantrasyonlarda anaerobik çürütücülere ilave edilerek $\mathrm{Fe}_{3} \mathrm{O}_{4}$ dozunun biyogaz üretimi üzerindeki etkileri incelenmiştir. $\mathrm{Fe}_{3} \mathrm{O}_{4}$ konsantrasyonu artması ile biyogaz artışı görülmüş ve $\mathrm{Fe}_{3} \mathrm{O}_{4}$ kullanılmayan kontrol düzeneklerindeki ortalama biyogaz hacmi 428,9 mL iken $0,3 \mathrm{~g} / \mathrm{L} \mathrm{Fe}_{3} \mathrm{O}_{4}$ ilavesinde $572,8 \mathrm{~mL}$ biyogaz elde edilmiştir.

Anahtar Kelimeler: Stabilizasyon, Anaerobik çürütme, Metan üretimi, Nanopartikül, $\mathrm{Fe}_{3} \mathrm{O}_{4}$

\section{Effects of Magnetic Nanoparticles on Biogas Production in Anaerobic Digester}

\begin{abstract}
Anaerobic digestion, one of the processes commonly used to stabilize sludge produced in wastewater treatment plants and to generate renewable energy, is a process performed by many groups of microorganisms. Nowadays, advances in nanotechnology, a new field for scientific research, have enabled nanoparticles to be used in many areas. The effects of nanoparticles on methane production and stabilization in anaerobic digesters have become a remarkable issue in recent years. One of the most known and widely used nanoparticles is $\mathrm{Fe}_{3} \mathrm{O}_{4}$. In this study, the effects of magnetic nanoparticles, especially $\mathrm{Fe}_{3} \mathrm{O}_{4}$ magnetic nanoparticles, on biogas production in anaerobic digesters were investigated by giving information about nanoparticle applications. In addition, $\mathrm{Fe}_{3} \mathrm{O}_{4}$ magnetic nanoparticle was synthesized in the laboratory using the co-precipitation method and its magnetic properties were evaluated. After $\mathrm{Fe}_{3} \mathrm{O}_{4}$ was synthesized, the effects of $\mathrm{Fe}_{3} \mathrm{O}_{4}$ dose on biogas production were investigated
\end{abstract}

*Sorumlu yazar (Corresponding author): Özlem DEMİ, odemir@harran.edu.tr 
by adding different concentrations to anaerobic digesters. Biogas increased with the increase in $\mathrm{Fe}_{3} \mathrm{O}_{4}$ concentration, and the average biogas volume in the control devices without $\mathrm{Fe}_{3} \mathrm{O}_{4}$ was 428.9 mL, while $572.8 \mathrm{~mL}$ biogas was obtained with the addition of $0.3 \mathrm{~g} / \mathrm{L} \mathrm{Fe}_{3} \mathrm{O}_{4}$.

Keywords: Stabilization, Anaerobic digestion, Methane production, Nanoparticle, $\mathrm{Fe}_{3} \mathrm{O}_{4}$

\section{GİRİs}

Atıksu arıtma tesislerinin sayısının artması, tesislerde üretilen çamur miktarının artışını da beraberinde getirmektedir. Atıksu arıtma tesislerinin karşılaştığı en büyük zorluklardan biri atık aktif çamurun çok fazla üretilmesidir. Atık aktif çamur arıtımı ve bertarafının temel amaçları, çamurda bulunan organik maddelerin stabilizasyonu, suyun bir kismının uzaklaştırılmasıyla atılacak çamur hacminin azalt1lmas1, patojenlerin imha edilmesi ve kullanılabilen yan ürünlerin toplanmasıdır. Atık aktif çamurun uygun olmayan bir şekilde arıtılması ve bertaraf edilmesi, ikincil kirliliğe neden olmakta ve çevreye önemli riskler taşımaktadır [1]. Bundan dolayı, çamur miktarını azaltabilen ve aynı zamanda enerji geri kazanımı sağlayabilen atık aktif çamur arıtım stratejileri son zamanlarda ilgi çeken bir konu haline gelmiştir [2].

Arıtma çamuru için enerji kazanım ve çevresel sürdürülebilirlik açısından en uygun yöntem olarak anaerobik çürütme önerilmektedir. Evsel ve endüstriyel atıksuların arıtımında kullanılan en eski arıtım teknolojilerindendir. Arıtma çamurlarının anaerobik olarak çürütülmesi modern atıksu arıtma tesislerinde yaygınlaşmaktadır. Anaerobik parçalanma sistemleri özellikle de büyük kapasiteli arıtma tesislerin önemli bir parçası haline gelmektedir [3]. Kısacası, anaerobik çürütücü, atıksu çamurunu stabilize etmek ve biyogaz için yenilenebilir enerji üretmek için en yaygın olarak kullanılan işlemlerden biridir $[4,5]$.

Nanoteknoloji, son on yılda bilim ve teknolojideki en önemli gelişmelerden biri olarak kabul edilmektedir. Nanometrik boyut aralığındaki parçacıklar nanopartiküller olarak adlandırılır. Boyut, büyük ölçüde bunların sentezi için kullanılan işleme bağlıdır. Nano boyut, hücre zarlarına nüfuz etme kabiliyetini belirlediği için biyolojik sistemler ile etkileşimin kardinal özelliğidir, böylece biyolojik bariyerler arasında geçişi, bağışıklık sistemi ile etkileşimi, alımını, absorpsiyonunu, dağılımını ve metabolizmasını kolaylaştırır [6]. Nanopartiküller, 1 ila $100 \mathrm{~nm}$ arasında boyutlara sahip olan ve yüzey yükü, yüksek yüzey alanı/hacim oranı nedeniyle yüksek reaktivite, yüksek özgüllük ve dağılabilirlik gibi bazı benzersiz spesifik fizikokimyasal özellikler ile karakterize edilen bir partikül grubu olarak tanımlanır [7]. Bu benzersiz özellikler nanopartikül maddelerin endüstriyel alanda kullanımları için avantaj sağlamaktadır. Yapısal özelliklerinin yanı sıra az atık oluşumu ve ekonomik olma özelliklerine de sahiptir [3].

Anaerobik çürütme işlemi, normalde üç basamaktan oluşur (hidroliz, asitlenme ve metanojenez), ilk adım olarak bilinen çamurun hidrolizine daha fazla dikkat edilir. Çamurun biyolojik enzimler tarafından hidrolizi, son yıllarda giderek daha fazla araştırılmaktadır ve çok sayıda enzimin (amilaz, proteaz, lipazlar ve endoglikanazların vs.), biyolojik olarak parçalanabilen partikül organik maddelerin hidrolizinde önemli bir rol oynadığı bildirilmektedir [8]. Anaerobik çürütmede asitleşme fazının performansı da son derece önemlidir, çünkü özellikleri ve kimyasal bileşimi sonraki metanogenezi doğrudan etkileyebilir. Ayrıca, bazı karmaşık organik atıklar için, hidroliz ve asit oluşumu anaerobik çürütme prosesi sırasında hız belirleyici adım olarak kabul edilmiştir [9].

Son y1llarda, metan üretimi ve proses stabilitesi için anaerobik çürütücülerde nanopartiküllerin eklenmesi büyük ilgi görmektedir [10]. Nanopartiküllerin ayrıca anaerobik çürütücü hidrolizini hızlandırdığ ve stabilize edilmiş çamur ürettiği belirlenmiştir $[5]$.

$\mathrm{Fe}_{3} \mathrm{O}_{4}$ manyetik nanopartiküllerin anaerobik çürütme üzerindeki etkisi ile ilgili az sayıda 
çalışmaya rastlanmaktadır. $\mathrm{Bu}$ nedenle, bu çalışmada, $\mathrm{Fe}_{3} \mathrm{O}_{4}$ tarafından salınan $\mathrm{Fe}^{+2}$ ve $\mathrm{Fe}^{+3}$ iyonlarının metanojenlerin aktivitesini artırması, $\mathrm{Fe}_{3} \mathrm{O}_{4}$ 'in bölgeler arası elektron transferini kolaylaştırması, $\quad \mathrm{Fe}^{+2}$ ve $\mathrm{Fe}^{+3}$ 'ün mikroorganizmalara besin sağlaması ve sülfür demirlerini engelleyerek sülfat indirgeyen bakterilerin anaerobik çürütme üzerindeki engelleyici etkisini azaltması gibi avantajlarından yola çıkılarak, $\mathrm{Fe}_{3} \mathrm{O}_{4}$ 'in anaerobik çürütücüdeki etkisi araştırılmıştır. Aynı zamanda, fazla $\mathrm{Fe}_{3} \mathrm{O}_{4}$ dozunun da toksik etki yapma yönü gözönünde bulundurularak anaerobik çürütücüde elde edilen için optimum $\mathrm{Fe}_{3} \mathrm{O}_{4}$ dozu bulunmaya çalışılmıştır. $\mathrm{Bu}$ çalışmada, nanopartikül çeşitleri, karakterizasyonu, sentezleri, uygulamalar1, özellikleri hakkında bilgiler verilmiș ve nanopartiküllerin, özellikle de $\mathrm{Fe}_{3} \mathrm{O}_{4}$ manyetik nanopartiküllerinin, atıksu arıtma tesislerindeki anaerobik çürütücüde performansları ile ilgi çalışmalar ele alınmıştır. $\quad \mathrm{Fe}_{3} \mathrm{O}_{4}$ manyetik nanopartikülü birlikte çökeltme yöntemi ile sentezlenmiş ve bu partikülün manyetik özellikleri incelenmiştir. Daha sonra, sentezlenen $\mathrm{Fe}_{3} \mathrm{O}_{4}$ laboratuvar ölçekli küçük anaerobik çürütücülere farklı konsantrasyonlarda eklenerek biyogaz üretimi üzerine etkileri araştırılmıştır.

\subsection{Anaerobik Çürütme ve Demir Oksit Nanoparçacıkların Etkisi}

Anaerobik çürütücü, atıksu artıma tesisi (A.A.T)'deki atıksu çamurunun hammaddesi ile çürütücüdeki toksik maddelere maruz kalma potansiyeline sahiptir. Organik ve inorganik olan kirleticiler, atıksu çamurunda A.A.T'deki yolu boyunca birikir ve daha sonra anaerobik çürütücülere taşınır. Bu kirleticiler, anaerobik çürütücünün sabit durumunu tehlikeye sokar. Bununla birlikte, stabilizasyon ve metan üretimini sürdürülebilir ve verimli bir şekilde elde etmek için sabit durumun anaerobik bir çürütücü içinde tutulması çok önemlidir [11].

Anaerobik çürütme, organik atıkları metan yan ürünü formunda yenilenebilir enerjiye dönüştürmek için en önemli tekniklerden biri olarak düşünülebilir, çünkü yakıt olarak işlem maliyetini düşürebilmektedir [12,13]. Biyolojik dönüşümü yüksek olan anaerobik çürütme, canlı hayvan gübresiyle başa çıkmada köklü bir teknolojidir ve enerji harcamasından tasarruf etmek ve yenilenebilir enerji üretmek için elektrik üretimi, konut 1sıtma vb. için kullanılabilir $[14,15]$.

Anaerobik çürütmenin genel sonucu, biyobozunur organik maddenin metan, karbon dioksit, hidrojen sülfit, amonyak ve yeni bakteri biyokütlesine neredeyse tamamen dönüşmesidir [16,17]. Anaerobik çürütme, bir mikroorganizma konsorsiyumu tarafından gerçekleştirilir ve $\mathrm{pH}$, sıcaklık, C/N oranı vb. gibi çeşitli faktörlere bağlıdır; bu nispeten yavaş bir işlemdir. Proses stabilitesi eksikliği, düşük yükleme oranları, kötüleşmeden sonra yavaş iyileşme ve atık bileşimi için özel şartlar anaerobik çürütme ile ilişkili diğer sınırlamalardan bazılarıdır [14,15]. Çürütücü içindeki sıcaklığın biyogaz üretim süreci üzerinde büyük etkisi vardır [18].

Anaerobik çürütme, organik maddeleri metan ve karbondioksite dönüştüren bir dizi mikrobiyal işlemden oluşur ve biyobozunmasına rağmen psikofilik $\left(<20^{\circ} \mathrm{C}\right)$, mezofilik $\left(25-40^{\circ} \mathrm{C}\right)$ veya termofilik $\left(50-65^{\circ} \mathrm{C}\right) \quad$ koşullar altında gerçekleşebilir. Mezofilik koşullar altında en yaygın olanıdır. Aynı zamanda aerobik arıtmadan daha yüksek yükleme oranları ve daha fazla patojen yıkımı sağlar [19]. Farklı çalışma koşulları altında çeşitli biyolojik ve kimyasal katkı maddelerini kullanarak mikrobiyal aktiviteyi uyararak biyogaz üretimini arttırmaya yönelik bazı girişimlerde bulunulmuştur. Biyogaz tesisinde katk1 maddelerinin kullanılması performansını önemli ölçüde artırabilir. Bir katkı maddesinin uygunluğunun, substrat tipine kuvvetlice bağlı olması beklenir [20].

$\mathrm{Fe}_{3} \mathrm{O}_{4}$ nanoparçacıkları, süper paramanyetik, toksik olmayan ve biyo-uyumlu özelliklerinden dolayı metan üretimini ve substrat bozulmasinı arttırmak için anaerobik çürütmede uygulanmıştır. Anaerobik çürütücülerde, demir nanopartiküller ilavesinin biyogaz işlem performansını stimüle ve stabilize ettiği gösterilmiştir Demir nanopartikülleri kararsızdır ve yavaşça çözünebilir ve $\mathrm{Fe}^{+2}$ ve $\mathrm{Fe}^{+3}$ iyonları sağlayabilir. Aslında, bu demir iyonları kofaktör ve enzimlerin temel 
bileşenleridir ve anaerobik çürütücülere eklenmesi, Archaea mikroorganizmalarının (metanojen mikroorganizma) etkinliğini artırabilir. Bununla birlikte, $\mathrm{Fe}^{+2}$ iyonlarının eklenmesi sadece ilk 24-48 saatinde biyogaz üretimini artırabilir ve yüksek demir iyon konsantrasyonunun bakteriler üzerinde toksisite etkisi vardır, bu da biyogaz üretimini azaltır. $\mathrm{Bu}$ nedenle, demir nanopartikülleri, doymamışlık ve biyolojik olarak kullanılabilir olması nedeniyle anaerobik çürütme işlemi için optimal demir konsantrasyonunu sürdürmek için iyi bir adaydır. Birçok çalışma, demir nanopartikül takviyesinin, sentrofik metanojenezde yer alan bölgeler arası elektron transferini (DIET) kolaylaştırabileceğini öne sürmüştür [21]. Çalışmalar ayrıca, $\mathrm{Fe}^{+2}$ ve $\mathrm{Fe}^{+3}$ mikroorganizmalara besin sağladığını ve sülfür demirlerini engellediğini, böylece sülfat azaltıcı bakterilerin anaerobik çürütücü üzerindeki engelleyici etkisini azalttığını göstermiştir [22].

Küçük nanopartiküller arasında manyetik etkiler olduğundan, manyetik alan varlığında ototrofik bakterilerin aktivitesini artacaktır. $\mathrm{Bu}$ arada, ototrofik bakterilerin daha yavaş çoğalması nedeniyle, bir taşıyıcıya bağlanmak, reaktörde büyümeleri ve zenginleşmeleri için pozitif etki yaratmaktadır [23]. Literatürde, manyetik nanopartülllerin arasındaki etkileşimlerin, bakterilerin aktivitelerini artırabileceği belirtilmiştir [24].

\section{2. ÖNCEKİ ÇALIŞMALAR}

Zhang ve arkadaşları (2011), yaptığı çalışmada, sıfır değerlikli demir (ZVI) anaerobik bir reaktöre eklendiğinde, atık su arıtımı için kullanılan reaktörün düşük sıcaklıklarda ve kısa bir hidrolik alıkonma süresi altında daha fazla KOİ giderimi elde etmesini sağlayan metanojenlerin büyümesini desteklediğine dair doğrudan kanıtlar sağlamıştır. Reaktöre sıfır değerli demir (ZVI) eklenmesinin metan üretiminde \% 17 artış sağladığı sonucuna varmışlardır [25].

$\mathrm{Mu}$ ve arkadaşları (2011), dört metal oksid nanoparçacığını (nano- $\mathrm{TiO}_{2}$, nano- $\mathrm{Al}_{2} \mathrm{O}_{3}$, nano$\mathrm{SiO}_{2}$ ve nano- $\mathrm{ZnO}$ ) araştırmış ve sadece nano-
ZnO'nun metan üretimi üzerinde inhibe edici etkisi olduğu ve nano-ZnO'nun doza bağımlı olduğu sonucuna varmıştır. Düşük nano- $\mathrm{ZnO}(6 \mathrm{mg} / \mathrm{g}$ AKM) metan oluşumu üzerinde herhangi bir etki yaratmamıştır [26].

Liu ve arkadaşları (2015), anaerobik granüler çamur reaktörlerinde ZVI ilavesiyle geliştirilmiş metan üretimini ve sülfat indirgemesini tanımlamak için farklı çalışma koşullarına bağlı iki farklı matematiksel model geliştirmişlerdir. Sonuçlar, ZVI'nin metan üretimini arttırmak için propiyonat bozunmasını ve metanojenezi doğrudan teşvik ettiğini göstermektedir [27].

Zhou ve arkadaşları (2015), yaptğı araştırmada, aktif çamur anaerobik hidrolizinin teşvik edilmesi için uygulanabilir bir strateji sunulmuştur. Desteklenen demir porfirinin, fazla tortunun anaerobik hidrolizi üzerine bir biyomimik katalizör olarak uygulanması araştırılmıştır. Optimal koşullar altında, KOİं KOİं ve UAKM azaltma oran1, ilk \%13,2 ve \%17,0'den (kontrol testi) sırasıyla \%25,7 ve \%35,3'e yükselmiştir. Sonuçlar, bu desteklenmiş biyomimik katalizörün, çamur hidrolizinin teşvikinde dikkate değer bir performans sergilediğini göstermiştir [8].

Suanon ve arkadaşları (2016), biyogaz üretimini iyileştirmek için mezofilik anaerobik çürütme (AÇ) işlemlerinde $(37 \pm 1 \mathrm{C})$ iki farklı demir nanopartikülü sıfır değerlikli demir (nZVI) ve manyetit $\left(\mathrm{Fe}_{3} \mathrm{O}_{4}\right)$ kullanmışlardır. Ayrıca demir nanopartikülleri olan ve olmayan çamurun AÇ sırasında ağır metal $(\mathrm{Cd}, \mathrm{Co}, \mathrm{Cu}, \mathrm{Zn}, \mathrm{Ni}$ ve $\mathrm{Cr})$ spekülasyonu değişiklikleri araştırılmıştır. Sonuç olarak, uygun şekilde kullanıldığında demir nanoparçacıkları sadece biyogaz verimini artırmakla kalmayıp AÇ prosesi sırasında metallerin mobilizasyonunu düzenleyip ve kontrol ettiği ve daha fazla çalışmaya ihtiyaç duyulduğunu bildirmişlerdir [5].

Eduok ve arkadaşları (2017), nanopartiküllerin çamur çürütme performansı üzerindeki potansiyel etkisini araştırmak için $150 \mathrm{~L}$ pilot anaerobik çürütücüye gümüş oksit, titanyum dioksit ve çinko oksit karışımıyla eklenmiş birincil ve atık aktive edilmiş çamur karışımı ile beslemişlerdir. 
Sonuçlar, mikrobik bolluğu ve çeşitliliği azaltırken, bazı organizmalara rekabet avantajı sunan Fusobacteria, Actinobacteria ve Trojanhorse benzeri etkenlerin esnekliğine dair çarpıcı kanıtlar sunmaktadir [28].

Ma ve arkadaşları (2018), yaptığı çalışmada asidifikasyon fazına mezofilik ve oda sıcaklığında demir oksit-zeolit katkı maddesi eklenmiştir. İlave edilen katkı maddesi sayesinde, daha yüksek çözünür kimyasal oksijen ihtiyacı (KOİ $)$ konsantrasyonu (\%21,53-227,30) ve daha iyi lignoselülozik degradasyon açısından önemli ölçüde geliştirilmiş hidroliz/fermentasyon elde edilmiştir [29].

Zhang ve arkadaşları (2019), anaerobik çürütme (AÇ) reaktörlerine sırasıyla nano sıfır değerlikli demir (nZVI) ve $\mathrm{Fe}_{3} \mathrm{O}_{4}$ Nanopartiküller ilave edilip, AÇ işlemi, $\mathrm{pH}$, biyogaz verimleri ile toplam katıların (TS), uçucu katıların (VS) ve çözünür kimyasal oksijen talebinin (sCOD) giderim oranı ile değerlendirilmiştir. AÇ biyogaz üretiminin kinetiğini araştırmak için üç model kullanılmıştır. Uygun dozda nZVI veya $\mathrm{Fe}_{3} \mathrm{O}_{4}$ nanopartiküllerin eklenmesi sonucunda çamurun anaerobik çürütülebilirliğini arttırdığını gözlemlemiştir. 80 günlük mezofilik işlem sonrasında En yüksek kümülatif biyogaz verimi, $\mathrm{Fe}_{3} \mathrm{O}_{4}$ nanopartiküller 137,13 L, nZVI ile 140,34 L'dir. Bu iki reaktörün kümülatif biyogaz üretimi, $\% 15,70$ ve $\% 13,44$ 'e kadar önemli ölçüde arttırdığını bildirmişlerdir [30].

Romero-Güiza ve arkadaşları (2019), serbest nitröz asit (FNA) ile ikincil çamur ön işleminin, anaerobik çürütme sırasında oluşan metan üretiminin performansı araştırmışlardır. Sürekli 2 reaktörde ikincil çamur $50-250 \mathrm{mg} \mathrm{NO} \mathrm{N}_{2} \mathrm{~N}-\mathrm{N} / \mathrm{L}$ aralığında 5 saat boyunca $6,7 \mathrm{pH}$ 'da, nitrit ile ön arıtımdan geçirilmiştir. Biyokimyasal metan potansiyel testleri (BMP'ler) elde edilen sonuçlar, $150 \mathrm{mg} \mathrm{NO}_{2} \mathrm{~N}-\mathrm{N} / \mathrm{L}$ ve metan artış1 \%24'dür. Sonuçlar, her iki reaktörde metan gelişimi açısından çok benzer bir performans ortaya çıkmıştır. Bu nedenle metan verimini arttırmak için çamur asitleştirmeye gerek olmadığ bildirilmiştir [31].
Abdelsalam ve arkadaşları (2016), mikro elementler olarak iz metallerin, hayvan dişkıları, mahsul artıkları veya herhangi bir başka organik atık türüyle işletilen tarımsal biyogaz çürüme performansı ve stabilitesi üzerinde çok önemli bir rol oynadığını ve $\mathrm{Ni}$ ve $\mathrm{Fe}_{3} \mathrm{O}_{4}$ nanopartiküllerinin metan verimini arttırdığı sonucunu bildirmişlerdir [6].

Casals ve arkadaşları (2014), reaktörde $60^{\circ} \mathrm{C}$ 'de $37^{\circ} \mathrm{C}$ 'de sentezlenmiş $\mathrm{Fe}_{3} \mathrm{O}_{4}$ nanopartikülleri (7 nm) kullanmış ve metan üretiminde \%234 artış olduğunu bildirmişlerdir. Sonuç olarak anaerobik çürütücüde optimal demir konsantrasyonlarını korumanın, bakteriyel aktiviteyi iyileştirmek için kritik bir adım olduğunu varsaymışlardır [32].

Goyal ve arkadaşları (2018), çok fonksiyonlu $\left(\mathrm{ZnO}-\mathrm{Fe}_{3} \mathrm{O}_{4}\right)$ nanokompozitler için bir sentez yolu geliştirip, $\mathrm{Fe}_{3} \mathrm{O}_{4}$ nanoparçacıkları $\mathrm{ZnO}$ yüzeyi üzerinde işlemişlerdir. $\left(\mathrm{ZnO}-\mathrm{Fe}_{3} \mathrm{O}_{4}\right)$ nanokompozitlerindeki bileşenlerin bileşimi, sahadan çıkarılması gereken kirliliklerin türüne bağlı olarak değişstirilebilirliği ve $\mathrm{Cu}$ (II) ve $\mathrm{Pb}$ (II) için $\mathrm{pH} 5,5$ 'te sirasıyla maksimum $4,1 \mathrm{mg} / \mathrm{g}$ ve $3,68 \mathrm{mg} / \mathrm{g}$ adsorpsiyon kapasitesi gözlemlenmiştir. $\mathrm{Bu}$ çok fonksiyonlu nanokompozitler, organik boyaların, inorganik metal iyonlarının ve mikrobiyal kontaminasyonun giderilmesi için etkili bir yeniden kullanılabilir nano-adsorban görevi görmekte olduğunu, aynı zamanda ZF nanokompozitlerini, su arıtımı için hızlı, etkili, ucuz ve çekici bir seçenek sunmak için tek bir platform sistemi olarak gösterdiğini bildirmişlerdir [33].

Demirel ve Scherer (2011), Fe ilavesiyle biyogaz üretimindeki iyileşmenin inek gübresi ve kanatlı kumu kullanılarak araştırmıştır. Her iki substrat için $\mathrm{FeSO}_{4}$ ilavesi, biyogaz üretimini ve $\mathrm{CH}_{4}$ biyogaz içeriğini iyileştirmiştir. $\mathrm{Su}$ sümbülü sığır gübresinin anaerobik çürütme sırasında $\mathrm{FeCl}_{3}$ ilavesinin, biyogaz üretiminde \%60'tan fazla bir artışa yol açtığı bildirilmiştir. Ayrıca, domuz dışkısı ile kesikli deneyleri sırasında $\mathrm{FeCl}_{2}$ ilavesinin sülfit inhibisyonunu önlediği belirtilmiştir [34]. 
$\mathrm{Mu}$ ve arkadaşları (2011), dört metal oksid nanoparçacı̆̆ını (nano- $\mathrm{TiO}_{2}$, nano- $\mathrm{Al}_{2} \mathrm{O}_{3}$, nano$\mathrm{SiO}_{2}$ ve nano-ZnO) araştırmış ve sadece nanoZnO'nun metan üretimi üzerinde inhibe edici etkisi olduğu ve nano-ZnO'nun doza bağımlı olduğu sonucuna varmıştır. Düşük nano-ZnO $(6 \mathrm{mg} /$ g-AKM) metan oluşumu üzerinde herhangi bir etki yaratmamıştır [26].

Zhou ve arkadaşları (2015), yaptığı araştırmada, aktif çamur anaerobik hidrolizinin teşvik edilmesi için uygulanabilir bir strateji sunulmuştur. Desteklenen demirporfirinin, fazla tortunun anaerobik hidrolizi üzerine bir biyomimik katalizör olarak uygulanması araştırılmıştır. Demirporfirinin tarafından modifiye edilen manyetik $\mathrm{Fe}_{3} \mathrm{O}_{4}$ nanoparçacıkları ayrıca bir silanasyon yöntemiyle sentezlenmiş ve X-1şını kırınımı (XRD), taramalı elektron mikroskobu (SEM), Fourier dönüşümü kızılötesi spektroskopisi (FTIR) ile karakterize edilmiştir. Sonuçlar, bu desteklenmiş biyomimik katalizörün, çamur hidrolizinin teşvikinde dikkate değer bir performans sergilediğini göstermiştir. Optimal koşullar altında, $\mathrm{KOI}_{C ̧} / \mathrm{KOI}_{\mathrm{T}}$ ve UAKM azaltma oran1, ilk \%13,2 ve \%17,0'den (kontrol testi) sırasıyla \%25,7 ve \%35,3'e yükselmiştir. Sonuçlar, nötr yakın pH değerlerinde biyomimik katalizörlerin mevcudiyetinde fazla tortunun hidrolizinin, alkalin ve asidik $\mathrm{pH}$ aralıklarında yapılanlardan daha verimli olduğunu göstermiştir. Geri dönüşüm çalışmaları, biyomimik katalizörlerin, katalitik kapasitede önemli bir değişiklik olmadan birkaç kez kullanılabileceğini göstermiştir [8].

Barrena ve arkadaşları (2009), $\mathrm{Fe}_{3} \mathrm{O}_{4}, \mathrm{Ag}$ ve $\mathrm{Au}$ nanopartiküllerinin salatalık ve marul bitkilerinin çimlenme evresi, deniz bakterisi olan Photobacterium phosphoreum ve anaerobik çamur üzerindeki etkilerini araştırmışlardır. Anaerobik mikroorganizmalar üzerindeki etkilerin belirlenmesi amacıyla anaerobik aşı çamur evsel katı atıkların anaerobik olarak çürütüldüğü bir tesisten alınmış ve sonuçlar toplam biyogaz üretim miktarının ölçümü üzerinden yapılan anaerobik toksisite testi ile değerlendirilmiştir. $\mathrm{Fe}_{3} \mathrm{O}_{4}, \mathrm{Ag}$ ve $\mathrm{Au}$ nanopartikülleri için sirasıyla 18,16 ve 10 $\mathrm{mg} / \mathrm{L}$ konsantrasyonların kullanıldığı anaerobik test 21 gün sürdürülmüştür. Elde edilen bu değerlerin istatistiksel değerlendirmesi sonucunda her üç nanopartikülün de gaz üretimine herhangi bir etkisi olmadığ saptanmıştır. Her ne kadar bu çalışmada inhibisyon etkisi tespit edilemediyse de inorganik nanopartiküllerin çevre ile etkileşimlerinin daha derinlemesine araştırılması gerektiğini belirtmişlerdir (Barrena ve arkadaşları, 2009).

Zhang ve arkadaşları (2020), biyogaz üretimi ve atık çamur azaltımını arttırmak için iki aşamalı anaerobik çürütmede $\mathrm{Fe}_{3} \mathrm{O}_{4}$ nanoparçacıkları (FNP) uygulanmıştır. En uygun FNP dozu, $100 \mathrm{mg} / \mathrm{L}, 11,9 \mathrm{~mL} \mathrm{H}_{2} / \mathrm{gVS}$ hidrojen ve $109,8 \mathrm{~mL}$ $\mathrm{CH}_{4} / \mathrm{gVS}$ metan verimi gözlemlenmiştir. Bu, kontrolünkine kıyasla \%15,1 hidrojen verimi ve \%58,7 metan verimini arttırdığını bildirmişlerdir [21].

Abdelsalam ve arkadaşları (2017), nanopartiküllerin biyogaz ve metan üretimi üzerindeki etkilerini, özel olarak tasarlanmış bir seri anaerobik sistem kullanarak incelemiştir. Bu amaçla, farklı konsantrasyonlardaki Demir $(\mathrm{Fe})$ ve Demir Oksit $\left(\mathrm{Fe}_{3} \mathrm{O}_{4}\right)$ nanoparçacıklarının biyogaz ve metan üretimi üzerindeki etkilerini incelemek için 2L biyodizel üretilmiştir. Nanopartikül katk1 maddelerinin en iyi sonuçları, $20 \mathrm{mg} / \mathrm{L} \quad \mathrm{Fe}$ nanopartikül ve $20 \mathrm{mg} / \mathrm{L} \quad \mathrm{Fe}_{3} \mathrm{O}_{4}$ manyetik nanopartiküllerin $(\mathrm{p}<0,05)$ olduğu biyogaz ve metan üretiminin istatistiksel analizine (M-Stat kullanarak en küçük fark) dayalı olarak seçilmiştir. En yüksek spesifik biyogaz ve metan üretimi, $20 \mathrm{mg} / \mathrm{L} \mathrm{Fe}_{3} \mathrm{O}_{4}$ manyetik nanopartiküllerle $584 \mathrm{~mL}$

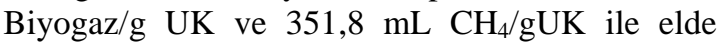
edilmiştir. Kontrol sisteminde ise spesifik biyogaz üretimi 352,6 mL Biyogaz/gUK iken metan üretimi de 179,6 $\mathrm{mL} \mathrm{CH}_{4} / \mathrm{g}$ UK'dir [23].

Noonari ve arkadaşları (2020), $\quad \mathrm{Fe}_{3} \mathrm{O}_{4}$ nanopartiküllerin anaerobik çürütücü üzerine etkilerini araştırarak maksimum metan üretimi elde etmek ve $\mathrm{Fe}_{3} \mathrm{O}_{4}$ nanopartiküllerinin dozajını optimize etmek için çalışmalar yapmıştır. Bununla birlikte, $\mathrm{Fe}_{3} \mathrm{O}_{4}$ nanopartiküllerinin metan üretimini arttırdığını ve çürütme sürecini stabilize ettiği gözlemlenmiştir. İlk adımda, $\mathrm{Fe}_{3} \mathrm{O}_{4}$ nanoparikülleri sentezlenmiş ve karakterize edilmiştir. İkinci aşamada, farklı dozlardaki $\mathrm{Fe}_{3} \mathrm{O}_{4}$ nanopartiküllerin 
manda içeriği karışım oranıyla (metan verimi açısından) kanola samanı üzerindeki etkileri incelenmiştir. Üçüncü adımda, ikinci fazın aynı dozlarında $\mathrm{Fe}_{3} \mathrm{O}_{4}$ nanopariküllerin manda içeriği karışım oranına sahip (metan verimi açısından) muz bitkisi atıkları üzerindeki etkileri incelenmiştir. Son aşamada, ikinci ve üçüncü adımlar için $\mathrm{Fe}_{3} \mathrm{O}_{4}$ dozu optimize edilmiş ve metan üretimi ile karşılaştırılmıştır. Deneysel sonuçlar tüm dozların birlikte yaşama ve metan üretimindeki mikrobiyal aktiviteleri uyardığını göstermiştir. Maksimum metan verimi $256 \mathrm{mLCH}_{4} / \mathrm{gUK}$ ve $202,3 \mathrm{mLCH}_{4} / \mathrm{gUK}$, kontrolle karşılaştırıldığında sırasıyla kanola samanı ve muz bitkisi atıkları için $0,81 \mathrm{mg}$ ve $0,5 \mathrm{mg}$ dozajında elde edilmiştir [10].

\section{MATERYAL VE METOT}

\subsection{Materyal}

\subsubsection{Birlikte Çökeltme Yöntemi ile $\mathrm{Fe}_{3} \mathrm{O}_{4}$ Sentezi}

Deneysel olarak, iyi tanımlanmış ebat, şekil ve malzeme özelliklerine sahip nanopartiküllerin sentezi büyük önem taşımaktadır. $\mathrm{Fe}_{3} \mathrm{O}_{4}$, birlikte çökeltme sentez yöntemi kullanılarak sentezlenmiştir.

$40 \mathrm{~mL}$ saf su içerisine,

$$
\begin{aligned}
& >\mathrm{FeCl}_{3} \cdot 6 \mathrm{H}_{2} \mathrm{O}(1,62 \mathrm{~g}) \\
& >\mathrm{FeSO}_{4} \cdot 7 \mathrm{H}_{2} \mathrm{O}(1,39 \mathrm{~g})
\end{aligned}
$$

eklenerek çözünene kadar (5-10 dk) mekanik karıştırıcıya konulmuştur. Karıştırıcıdan çıkan çözeltiye $5 \mathrm{~mL} 1 \mathrm{~N} \mathrm{NaOH}$ eklenerek, karıştırıcı sonrası siyah parçacıkların oluşumu gözlemlenmiştir. Ardından hazırlanan çözelti $70^{\circ} \mathrm{C}$ sicak su banyosunda $30 \mathrm{dk}$ boyunca bekletilmiştir. $\mathrm{Bu}$ aşama bittikten sonra $5 \mathrm{~mL} 3 \mathrm{~N}$ $\mathrm{NaOH}$ eklenip tekrar çözünene kadar manyetik karıştırıcıya konmuştur.

Hazırlanan çözelti $3000 \mathrm{rpm}$ hızda $20^{\circ} \mathrm{C}$ 'de $10 \mathrm{dk}$ boyunca santrifüjlenmiştir. Çökeltme işlemi sonrası parçacıklar üst suyundan ayrılarak saf su ile yıkanmıştır. $\mathrm{Bu}$ işlem $5 \mathrm{kez}$ tekrarlanmıştır [36].
Yan ürünlerinden ayrılan parçacıklar son işlem olarak etüve konularak $106^{\circ} \mathrm{C}$ 'de 24 saat boyunca kurumaya bırakılmıştır. Her türlü olası sorunun önüne geçilmek için hazırlanan parçacıklar cam kavanoz içerisinde saklanmıştır [37]. Sentezleme aşamaları Şekil 1'de gösterilmiştir.

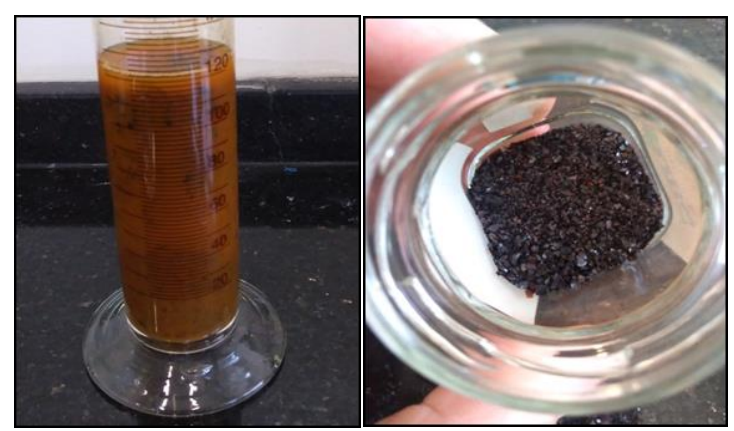

Şekil 1. $\mathrm{Fe}_{3} \mathrm{O}_{4}$ sentezleme aşamaları

\subsubsection{Deneysel Düzenek ve Anaerobik Çürütücülerin İşletimi}

$\mathrm{Bu}$ çalışmada kullanılan atık çamur, Şanlıurfa Biyolojik Atıksu Arıtma Tesisi'nin ikincil sedimantasyon tankından alınmıș ve aşı çamur, tesisinin sindirim tankından toplanmıştır. Toplanan ham atı çamur bekletilmeden hemen kullanılmıştır.

Tüm reaktörler kullanılmadan önce ön işlemlerden geçirilmiş, hiçbir sorun teşkil etmeyecek şekilde kullanıma hazır hale getirilmiştir. $500 \mathrm{~mL}$ çalışma hacmine sahip laboratuvar ölçekli anaerobik reaktörler kullanılmıştır. 5 tekrarlı 7 doz, 5 tekrarlı 1 doz olmak üzere toplamda 40 reaktör tasarlanmıştır. Her reaktör için $250 \mathrm{~mL}$ ham çamur, $70 \mathrm{~mL}$ aşı çamuru (anaerobik) eklenmiştir. $\mathrm{Bu}$ işlemlerden sonra $\mathrm{Fe}_{3} \mathrm{O}_{4}$ nanoparçacıkları da ilave edilerek fermente oluncaya kadar karıştırılmıştır. Reaktör için kullanılacak dozlar Çizelge 1'de verilmiştir.

Mikrobiyal hücreleri bozmak ve atık çamurun anaerobik sindirim etkinliğini arttırmak için atık çamur mezofilik koşullarda $\left(30-40^{\circ} \mathrm{C}\right)$ çamur çökmeyecek şekilde sürekli çalkalanmıştır. Bu aşama 22 gün sürmüştür. Çalışmada kullanılan 
örnek reaktör Şekil 2'de ve reaktör kurulumu Şekil 3'te gösterilmiştir.

Çizelge 1. Reaktör için kullanılacak dozlar

\begin{tabular}{|c|c|c|}
\hline \multicolumn{2}{|c|}{ Reaktör Serisi } & \multirow{2}{*}{$\begin{array}{c}\mathrm{Fe}_{3} \mathrm{O}_{4} \text { Konsantrasyonu } \\
(\mathrm{g} / \mathrm{L})\end{array}$} \\
\hline & $\begin{array}{c}\text { Reaktör } \\
\text { say1s1 }\end{array}$ & \\
\hline Kontrol & & 0 \\
\hline 25 & 5 & 0,025 \\
\hline 50 & 5 & 0,05 \\
\hline 100 & 5 & 0,1 \\
\hline 150 & 5 & 0,15 \\
\hline 200 & 5 & 0,2 \\
\hline 250 & 5 & 0,25 \\
\hline 300 & 5 & 0,3 \\
\hline
\end{tabular}

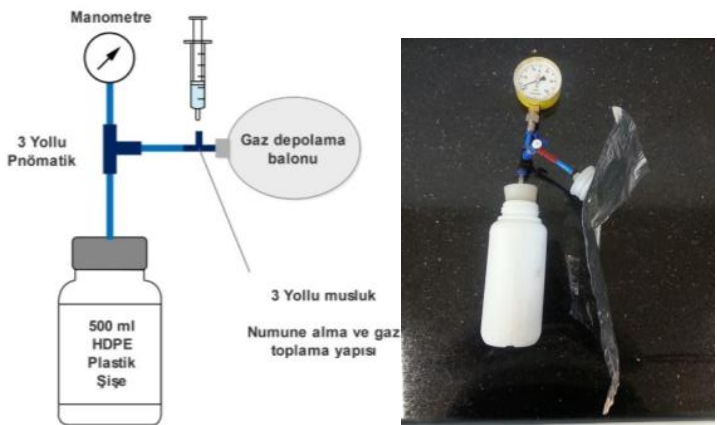

Şekil 2. Çalışmada kullanılan örnek reaktör şeması

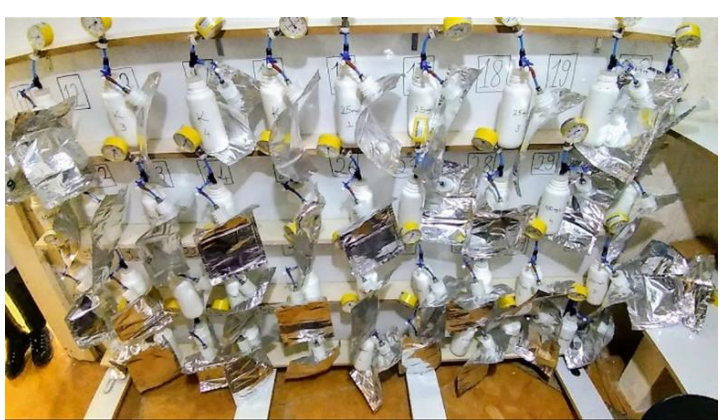

Şekil 3. Reaktör kurulumu

\subsubsection{Biyogaz Hacminin Belirlenmesi}

Yöntem olarak, biyogaz üretimi için gerekli olan anaerobik şartlar, mezofilik sıcaklık ve katı madde oranı belirlenip reaktörler kurulmuştur. Kurulan tüm reaktörlerin hava sızdırmazlığı kontrol edilip, reaktörde oluşan biyogaz çıkışları gözlenmiştir. 22 günlük bekleme süresi sonrası reaktörler açılıp biyogaz çıkışları hesaplanmıştır. Biyogaz çıkışları Şekil 4'te gösterilmiştir.

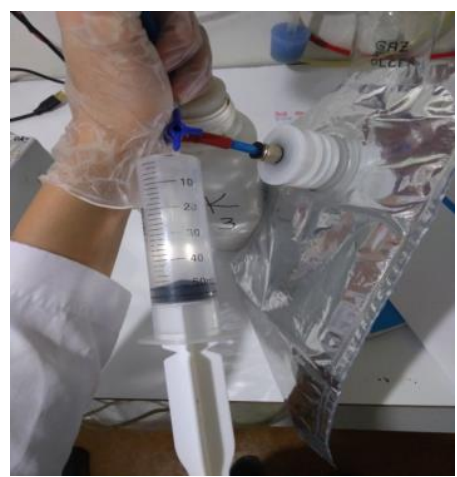

Şekil 4. Biyogaz çıkışı

\subsubsection{Kimyasal Analizler}

Anaerobik çürütücülerde kullanılan geri devir çamuru ve anaerobik çamurun $\mathrm{pH}$, sicaklık ve iletkenliği Hanna Instruments pH 211 tezgah ölçekli pH metre ile ölçülmüştür. Toplam kat1 madde ve organik madde ile çözünmüş KOİ analizleri ise Standard Metotlar'a göre yapılmıştır [38]. Aynı şekilde sentezlenmiş manyetik $\mathrm{Fe}_{3} \mathrm{O}_{4}$ nanopartiküllerin XRD analizleri daha önceki bir çalışma da [37] kullanılmış olup bu çalışmada da sunulmuştur.

\section{ARAŞTIRMA BULGULARI VE TARTIŞMA}

\subsection{Sentezlenmiş $\mathrm{Fe}_{3} \mathrm{O}_{4}$ ve Manyetik Özellikleri}

Sentezlenen manyetik $\mathrm{Fe}_{3} \mathrm{O}_{4}$, Şekil 5'te gösterilmiştir.

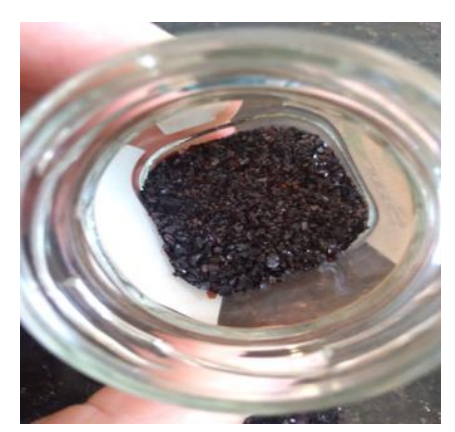

Şekil 5. $\mathrm{Fe}_{3} \mathrm{O}_{4}$ nanoparçacıkları 
XRD analizi sentezlenen nanoparçacıkların kristal yapısını ve büyüklüğünü bulmak için kullanılan bir tekniktir. Sentezden sonra elde edilen ürün üzerindeki ana oksidasyon analizinin sonuçları Çizelge 2'de gösterilmektedir [37]. Bu sonuçlara göre, örnekte \%93,73 Fe, \%1,12 Si ve 0,42 ppm Mn bulunmaktadır. Çizelge 3 'te verilen XRD analiz sonuçlarına göre, sentezlenen ürünün kimyasal formülünün $\mathrm{Fe}_{3} \mathrm{O}_{4}$ olduğu ve manyetik özelliğe sahip olduğu doğrulanmıştır [37].

Çizelge 2. Elemental analizi

\begin{tabular}{|l|c|c|c|}
\hline Element & Si & Fe & Mn \\
\hline Unit & \% & \% & ppm \\
\hline & 1,12 & 93,72 & 0,4 \\
\hline
\end{tabular}

Çizelge 3. XRD analizi

\begin{tabular}{|c|c|c|c|c|c|}
\hline$\%$ & Ref. Code & Score & Compound Name & $\begin{array}{c}\text { Dislacement } \\
\left({ }^{\circ} \mathbf{2} \text { Th. }\right)\end{array}$ & $\begin{array}{c}\text { Chemical } \\
\text { Formula }\end{array}$ \\
\hline $\mathbf{1 0 0}$ & $01-075-1609$ & 68 & Magnetite Low & 0,080 & $\mathrm{Fe}_{3} \mathrm{O}_{4}$ \\
\hline \multicolumn{2}{|c|}{ Pos. $\left({ }^{\circ} \mathbf{2}\right.$ Th. $)$} & Height $($ cts $)$ & FWHM $\left({ }^{\circ} \mathbf{2}\right.$ Th. $)$ & d-spacing $(\mathbf{A})$ & Rel. Int. $(\mathbf{\%})$ \\
\hline $\mathbf{2 , 0 5 2 8}$ & 35244,11 & 0,1368 & 43,00158 & 100,00 \\
\hline $\mathbf{3 , 7 1 1 1}$ & 5536,54 & 0,3192 & 23,78924 & 15,71 \\
\hline $\mathbf{3 0 , 2 4 3 0}$ & 451,64 & 0,5472 & 2,95285 & 1,28 \\
\hline $\mathbf{3 5 , 6 3 4 1}$ & 1310,98 & 0,3648 & 2,51749 & 3,72 \\
\hline $\mathbf{4 3 , 2 6 3 4}$ & 269,23 & 0,5472 & 2,02958 & 0,76 \\
\hline $\mathbf{5 7 , 1 8 5 4}$ & 263,30 & 0,5472 & 1,60955 & 0,75 \\
\hline $\mathbf{6 2 , 8 1 8 4}$ & 341,41 & 0,2736 & 1,47808 & 0,97 \\
\hline
\end{tabular}

\subsection{Anaerobik Çürütücüler için Kullanılan Çamurların Karakterizasyonu}

Bu çalışmada kullanılan atık çamur, Şanlıurfa Biyolojik A.A.T'nin proses geridevir tankından alınmış ve kullanılan aşı çamuru ise anaerobik çürütücü çıkışından alınmıştır. Toplanan ham atık çamur bekletilmeden hemen kullanılmıştır. Geri devir çamurun ve anaerobik aş1 çamurunun karakteristiği Çizelge 5'te verilmiştir

Çizelge 5. Geri devir çamuru ve anaerobik aş1 çamurun özellikleri

\begin{tabular}{|l|c|c|}
\hline Parametre & Substrat & Anaerobik Aş1 Çamur \\
\hline $\mathrm{pH}$ & 7,57 & 8,25 \\
\hline Sicaklık & 18,7 & 18,7 \\
\hline $\begin{array}{l}\text { Toplam Kat1 } \\
\text { Madde (mg/L) }\end{array}$ & 10000 & 8000 \\
\hline $\begin{array}{l}\text { Organik Madde } \\
\text { (mg/L) }\end{array}$ & 22000 & 16000 \\
\hline $\begin{array}{l}\text { Çözünmüş KOİ } \\
\text { (KOİç) mg/L) }\end{array}$ & 1280 & 3585 \\
\hline
\end{tabular}

\section{3. $\mathrm{Fe}_{3} \mathrm{O}_{4}$ Nanopartiküllerinin Anaerobik Çürütücüde Biyogaz Üretimi Üzerine Etkileri}

Yapılan çalışma sonucunda kurulan 5 set anaerobik çürütücüdeki biyogaz hacimleri Çizelge 6'da verilmiştir. Deneysel çalışma sonucunda ilave edilen $\mathrm{Fe}_{3} \mathrm{O}_{4}$ 'ün etkisinin daha net anlaşılabilmesi için konsantrasyon artışına göre biyogaz değişimi Şekil 6'da gösterilmiştir. Anaerobik çürütücüdeki biyogaz hacimleri ve $\mathrm{Fe}_{3} \mathrm{O}_{4}$ konsantrasyonu ile biyogaz değişiminden de anlaşıldığ çürütücüye eklenen $\mathrm{Fe}_{3} \mathrm{O}_{4}$ konsantrasyonu arttıkça biyogaz hacmi de artmaktadır.

$\mathrm{Fe}_{3} \mathrm{O}_{4}$ konsantrasyonun en yüksek olduğu $0,3 \mathrm{~g} / \mathrm{L}$ için 5 sette de en yüksek biyogaz hacimleri gözlenmiştir. $\mathrm{Fe}_{3} \mathrm{O}_{4}$ kullanılmayan kontrol reaktörler olarak hizmet eden reaktörlerde $\left(\mathrm{Fe}_{3} \mathrm{O}_{4}=0\right)$ ile kiyaslanacak olursa ortalama değerleri dikkate alınarak $\mathrm{Fe}_{3} \mathrm{O}_{4}$ ilave edilemeyen reaktörlerin ortalama biyogaz hacmi 428,8 mL iken, $\quad 0,3 \mathrm{~g} / \mathrm{L} \quad \mathrm{Fe}_{3} \mathrm{O}_{4}$ ilave edildikten sonra biyogazın ortalama hacmi 572,8 mL'ye yükselmiştir. 
Çizelge 6. Anaerobik çürütücülerdeki biyogaz hacimleri

\begin{tabular}{|c|c|c|c|c|c|c|}
\hline $\mathrm{Fe}_{3} \mathrm{O}_{4}$ konsantrasyonu $(\mathrm{g} / \mathrm{L})$ & \multicolumn{7}{|c|}{ Biyogaz $(\mathrm{mL})$} \\
\hline & 1. set & 2. set & 3. set & 4. set & 5. set & Ortalama \\
\hline 0 & 412 & 414 & 460 & 438 & 420 & 428,8 \\
\hline 0,025 & 424 & 350 & 316 & 382 & 384 & 371,2 \\
\hline 0,05 & 424 & 400 & 412 & 404 & 342 & 396,4 \\
\hline 0,1 & 408 & 424 & 422 & 424 & 326 & 400,8 \\
\hline 0,15 & 516 & 428 & 458 & 422 & 422 & 449,2 \\
\hline 0,2 & 422 & 422 & 424 & 600 & 422 & 458 \\
\hline 0,25 & 464 & 600 & 420 & 460 & 534 & 495,6 \\
\hline 0,3 & 612 & 656 & 516 & 526 & 554 & 572,8 \\
\hline
\end{tabular}

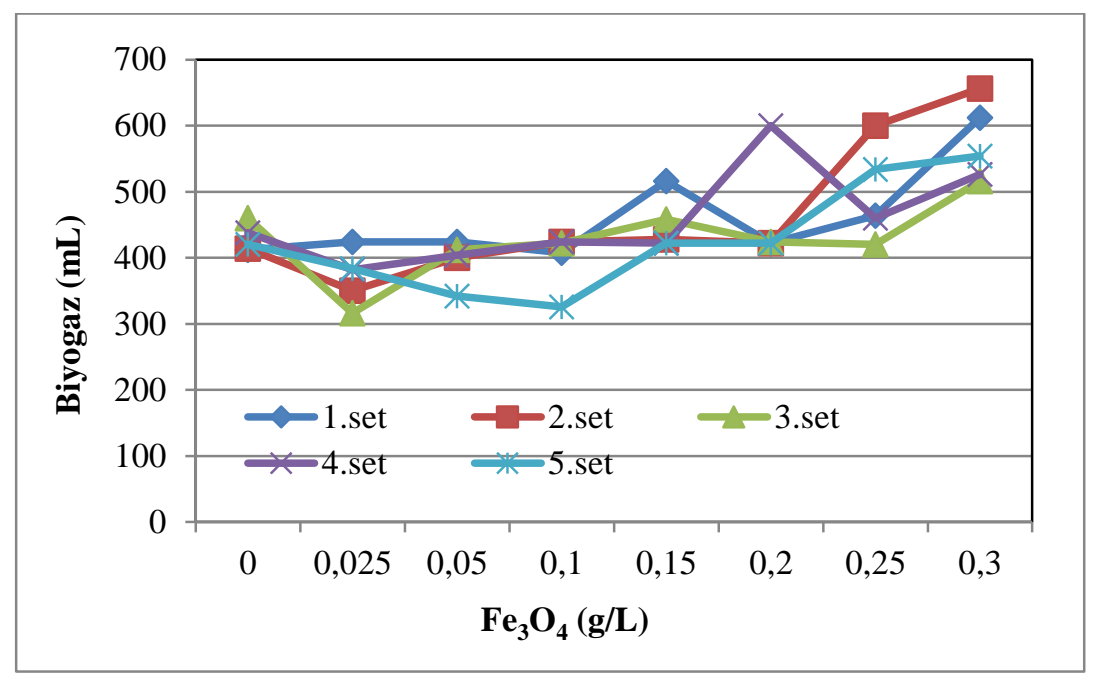

Şekil 6. $\mathrm{Fe}_{3} \mathrm{O}_{4}$ konsantrasyonu ile biyogaz değişimi

Nanopartiküllerin, anaerobik çürütücüye olan etkileri ve özellikle daha yüksek konsantrasyonlar üzerindeki yayınlanmış araştırmaların sayısı sınırlıdır ve çoğu, anaerobik çürütücü hidrolik alıkonma süreleri (HRT) dikkate alınarak daha uzun süreli değerlendirmeler içermemektedir.

Uzun süreli ve daha yüksek konsantrasyonların bir araya getirilmesiyle ilgili literatürdeki modelleme ile birlikte araştırma eksikliği göz önüne alındığında, farklı nanopartiküllerin anaerobik çürütücüye olası etkilerini biyokimyasal enerji üretimi ve atık yönetimi süreci olarak algılamak önemlidir [39].

Demir nanoparçacıkları, mikroorganizma için en fazla artan talebe sahip ve besin kaynağı olan nanopartiküllerden biri olarak bilinir. Demir metal,
Ag ve Cu'dan daha fazla reaktivite gücüne sahiptir [40].

Araştırmacılar, nanopartiküllerin de anaerobik çürüme sürecinde besin olarak etkileyici bir rol oynadığını gözlemlemişlerdir. $\mathrm{Fe}_{3} \mathrm{O}_{4}, \mathrm{NiO}, \mathrm{CuO}$, $\mathrm{ZnO}$, vb. kesikli reaktörlerde metanojenik aktivitelerin kayda değer şekilde artmasını sağlamıştır.

Methanobacterium thermo-autotrophicum gibi çeşitli metanojenlerin; Methanosarcina barkeri; Meth-anocorpusculum parvum ve Metanococcoides metilutens; Methanococcus vanielli ve Methanococcus, $\mathrm{Fe}, \mathrm{Ni}, \mathrm{Co}$, Se ve molibden (Mo) besin olarak gerekli görmüștür [10].

$\mathrm{Fe}_{3} \mathrm{O}_{4}$ nanopartikülleri, atıksu arıtımında sıklıkla kullanılır. $\mathrm{Fe}_{3} \mathrm{O}_{4}$ nanoparçacıklarının sulu 
çözeltilerden kadmiyum iyonu gidermek için birlikte çökeltilerek metal bağlanması için uygun fizikokimyasal özelliklere sahip olduğu bildirilmiştir [41]. $\quad \mathrm{Fe}_{3} \mathrm{O}_{4}$ nanoparçacıkları da boyaların hızlı bir şekilde uzaklaştırılmasını sağlayabilir [42]. Bununla birlikte, $\mathrm{Fe}_{3} \mathrm{O}_{4}$ nanoparçacıkları mıknatıs tozundan daha pahalıdır. Manyetik bir malzeme olarak bilinen $\mathrm{Fe}_{3} \mathrm{O}_{4}$, manyetik alan üretebilir ve $\mathrm{Fe}^{+2}$ ve $\mathrm{Fe}^{+3}$ 'e iyonize edilebilir. Harici bir manyetik alanın yardımıyla, katı-sıv1 ayrılma probleminin aşılmasında daha başarılı olmuştur [41]. Dahası, atıksu arıtımına $\mathrm{Fe}_{3} \mathrm{O}_{4}$ eklenmesi, aktif çamurdaki demir bileşiklerini mıknatıslayabilir ve çamur çökeltme verimliliği, manyetik kuvvetlerin parçacıkları birbirleriyle birleştirmesiyle artar [43,44].

$\mathrm{Fe}^{+2}$ 'in aktif çamurun düşük konsantrasyonlarda (2 mg/L) mikrobik bağlanmasına faydalı olduğu, ancak bağlanma seviyesinin yüksek konsantrasyonlarda (metal ilavesi olmadan) kontrol seviyesine düştüğü bildirilmiştir $[45,46]$.

Farklı araştırmacılar, anaerobik çürütmedeki üstün manyetik nanopartikül formunun $\mathrm{Fe}_{3} \mathrm{O}_{4}$ olduğunu bildirmişlerdir. $\quad \mathrm{Fe}_{3} \mathrm{O}_{4}$ 'ün nanoparçacıkları, anaerobik çürütücülerdeki mikrobiyal aktiviteler için $\mathrm{Fe}_{2} \mathrm{O}_{3}, \mathrm{NiO}, \mathrm{CuO}$ ve $\mathrm{Ag}$ 'den daha temel besinler olarak gösterilir [47].

\section{SONUÇLAR VE ÖNERILLER}

Anaerobik çürütücü, atıksu çamurunu stabilize etmek ve yenilenebilir enerji üretmek için kullanılan işlemlerden biridir. Nanopartiküllere anaerobik çürütücülere eklenmesi son yıllarda metan üretimi ve proses stabilitesi için büyük ilgi görmektedir.

Nanopartiküllerin ayrıca anaerobik çürütücü hidrolizini hızlandırdığı, metan verimini arttırdığ 1 ve stabilize edilmiş çamur ürettiği belirlenmiştir. $\mathrm{Fe}_{3} \mathrm{O}_{4}$ nanopartiküller, mikroorganizma için en fazla büyüyen talep ve besin kaynağı olan nanopartiküllerden biri olarak bilinmektedir. Uygun şekilde kullanıldığında $\quad \mathrm{Fe}_{3} \mathrm{O}_{4}$ nanopartikülleri, biyogaz verimini iyileştirmekle kalmamakta, aynı zamanda anaerobik çürütücü işlemi sırasında metallerin mobilizasyonunu düzenlemekte ve kontrol etmektedir. Anaerobik çürütücüde hidrolik alıkonma süresi yüksek seviyelere ulaştığında, kararlı durumunun bozabileceğini söylenebilir. Yapılan bu çalışma sonucunda, $\mathrm{Fe}_{3} \mathrm{O}_{4}$ konsantrasyonu artmas1 ile biyogaz artışı görülmüş ve $\mathrm{Fe}_{3} \mathrm{O}_{4}$ kullanılmayan kontrol düzeneklerindeki ortalama biyogaz hacmi 428,9 $\mathrm{mL}$ iken $0,3 \mathrm{~g} / \mathrm{L} \quad \mathrm{Fe}_{3} \mathrm{O}_{4}$ ilavesinde ise ortalama olarak 572,8 mL biyogaz elde edilmiştir

Sonuç olarak, tüm araştırmalar 1şı̆̆ında, atık su arıtımı ve diğer alanlarda dahil olmak üzere çeşitli uygulamalarda manyetik demir oksidin kullanımına son zamanlarda daha fazla ilgi duyulduğu ve demir oksitin anaerobik çürütücüde biyogaz ve metan üretimini olumlu etkilediği sonucuna varılabilmektedir.

\section{KAYNAKLAR}

1. Liu, X., Xu, Q., Wang, D., Zhao, J., Wu, Y., Liu, Y., Ni, B. J., Wang, Q., Zeng, G., Li, X., And Yang, Q., 2018. Improved Methane Production from Waste Activated Sludge by Combining Free Ammonia with Heat Pretreatment: Performance, Mechanisms and Applications. Bioresource Technology, 268, 230-236.

2. Wang, D., Liu, X., Zeng, G., Zhao, J., Liu, Y., Wang, Q., Chen, F., Li, X., Yang, Q., 2018. Understanding the Impact of Cationic Polyacrylamide on Anaerobic Digestion of Waste Activated Sludge. Water Research, 130, 281-290.

3. Ünşar, E.K., Perendeci, N.A., 2016. Nanopartiküllerin Çevresel Akıbetleri ve Anaerobik Parçalanma Prosesine Etkileri. Pamukkale Üniversitesi Mühendislik Bilimleri Dergisi, 22(6), 503-512.

4. Skinner, S.J., Studer, L.J., Dixon, D.R., Hillis, P., Rees, C.A., Wall, R.C., Cavalida, R.G., Usher, S.P., Stickland, A.D., Scales, P.J., 2015. Quantification of Wastewater Sludge Dewatering. Water Research, 82, 2-13.

5. Suanon, F., Sun, Q., Mama, D., Li, J., Dimon, B., Yu, C.P., 2016. Effect of Nanoscale Zerovalent Iron and Magnetite $\left(\mathrm{Fe}_{3} \mathrm{O}_{4}\right)$ on the Fate 
of Metals During Anaerobic Digestion of Sludge. Water Research, 88, 897-903.

6. Abdelsalam, E., Samer, M., Attia, Y.A., AbdelHade, M.A., Hassan, H.E., Badr, Y., 2016. Comparison of Nanoparticles Effects on Biogas and Methane Production from Anaerobic Digestion of Cattle Dung Slurry. Renewable Energy, 87, 592-598.

7. Turan, N.B., Erkan, H.S., Engin, G.O., Bilgili, M.S., 2019. Nanoparticles in the Aquatic Environment: Usage, Properties, Transformation and Toxicity-A Review. Process Safety and Environmental Protection.

8. Ruan, M., Zhang, X., Niu, C., Huang, B., Zhou, L., Zeng, G., Huang, D., 2015. A Feasible Strategy for Promoting Activated Sludge Hydrolysis by Using Ironporphyrin Modified $\mathrm{Fe}_{3} \mathrm{O}_{4}$ Nanoparticles as an Efficient Biomimic Catalyst. Chemical Engineering Journal, 280, 248-255.

9. Liu, Y., Zhang, Y., Quan, X., Li, Y., Zhao, Z., Meng, X., Chen, S., 2012. Optimization of Anaerobic Acidogenesis by Adding $\mathrm{Fe} 0$ Powder to Enhance Anaerobic Wastewater Treatment. Chemical Engineering Journal, 192, 179-185.

10. Noonari, A.A., Mahar, R.B., Sahito, A.R., Brohi, K.M., 2019. Anaerobic Co-digestion of Canola Straw and Banana Plant Wastes with Buffalo Dung: Effect of $\mathrm{Fe}_{3} \mathrm{O}_{4}$ Nanoparticles on Methane Yield. Renewable Energy, 133, 1046-1054.

11. Sezgin, Y., 2013. Çamur Azaltım Tekniklerindeki Yeni Gelişmeler Fotokatalitik Çamur Dezentegrasyonu, Namık Kemal Üniversitesi, Fen Bilimleri Enstitüsü, Yüksek Lisans Tezi, Tekirdağ, 82.

12. Feng, Y., Zhang, Y., Quan, X., Chen, S., 2014. Enhanced Anaerobic Digestion of Waste Activated Sludge Digestion by the Addition of Zero Valent Iron. Water Research, 52, 242250.

13. Holm-Nielsen, J.B., Al Seadi, T., OleskowiczPopiel, P., 2009. The Future of Anaerobic Digestion and Biogas Utilization. Bioresource Technology, 100(22), 5478-5484.

14. Wang, X., Yang, G., Feng, Y., Ren, G., Han, X., 2012. Optimizing Feeding Composition and Carbon-nitrogen Ratios for Improved Methane
Yield During Anaerobic Co-digestion of Dairy, Chicken Manure and Wheat Straw. Bioresource Technology, 120, 78-83.

15. Yin, D., Liu, W., Zhai, N., Yang, G., Wang, X., Feng, Y., Ren, G., 2014. Anaerobic Digestion of Pig and Dairy Manure Under Photo-dark Fermentation Condition. Bioresource Technology, 166, 373-380.

16. Kelleher, B.P., Leahy, J.J., Henihan, A.M., O'dwyer, T.F., Sutton, D., Leahy, M.J., 2002. Advances in Poultry Litter Disposal Technology-A Review. Bioresource Technology, 83(1), 27-36.

17. Roy, H.S., Satriyo, K.W., Praptiningsih, G.A., Salafudin, Agus, S.Y., Imam, W., Salundik, D., 2014. The Study of Optimization Hydrolysis Substrate Retention Time and Augmentation as an Effort to Increasing Biogas Productivity from Jatropha Curcas Linn. Capsule Husk at Two Stage Digestion, In Energy Procedia., 255-262.

18. El-Mashad, H.M., Van Loon, W.K.P., Zeeman, G., Bot, G.P.A., Lettinga, G., 2003. Reuse Potential of Agricultural Wastes in Semi-arid Regions: Egypt as a Case Study. Reviews in Environmental Science and Biotechnology, 2(1), 53-66.

19. Ravuri, H.K., 2013. Role of Factors Influencing on Anaerobic Process for Production of Bio Hydrogen: Future Fuel. International Journal of Advanced Chemistry, 1(2).

20. Yadvika, Santosh, Sreekrishnan, T.R., Kohli, S., Rana, V., 2004. Enhancement of Biogas Production from Solid Substrates Using Different Techniques-A Review. Bioresource Technology, 95(1), 1-10.

21.Zhang, Z., Guo, L., Wang, Y., Zhao, Y., She, Z., Gao, M., Guo, Y., 2020. Application of Iron Oxide $\left(\mathrm{Fe}_{3} \mathrm{O}_{4}\right)$ Nanoparticles During the Twostage Anaerobic Digestion with Waste Sludge: Impact on the Biogas Production and the Substrate Metabolism. Renewable Energy, 146, 2724-2735.

22. Gong, L., Yang, X., You, X., Wang, J., Zhou, J., Zhou, Y., Yang, J., 2019. Explore the Effect of $\mathrm{Fe}_{3} \mathrm{O}_{4}$ Nanoparticles (NPs) on Anaerobic Digestion of Sludge, Environmental Technology, 42(10),1542-1551. 
23. Abdelsalam, E., Samer, M., Attia, Y. A., Abdel-Hade, M.A., Hassan, H.E., Badr, Y. 2017. Influence of Zero Valent Iron Nanoparticles and Magnetic Iron Oxide Nanoparticles on Biogas and Methane Production from Anaerobic Digestion of Manure. Energy, 120, 842-853.

24. Ni, S-Q, Ni, J., Yang, N., Wang, J., 2013. Effect of Magnetic Nanoparticles on the Performance of Activated Sludge Treatment System. Bioresour Technol., 143, 555-61.

25.Zhang, Y., Jing, Y., Quan, X., Liu, Y., Onu, P., 2011. A Built-in Zero Valent Iron Anaerobic Reactor to Enhance Treatment of Azo Dye Wastewater. Water Science and Technology, 63(4), 741-746.

26. Mu, H., Chen, Y., Xiao, N., 2011. Effects of Metal Oxide Nanoparticles (Tio 2, $\mathrm{Al}_{2} \mathrm{O}_{3}, \mathrm{SiO}_{2}$ and Zno) on Waste Activated Sludge Anaerobic Digestion. Bioresource Technology, 102(22), 10305-10311.

27. Liu, Y., Zhang, Y., Ni, B.J., 2015. Zero Valent Iron Simultaneously Enhances Methane Production and Sulfate Reduction in Anaerobic Granular Sludge Reactors. Water Research, 75, 292-300.

28. Eduok, S., Ferguson, R., Jefferson, B., Villa, R., Coulon, F., 2017. Aged-engineered Nanoparticles Effect on Sludge Anaerobic Digestion Performance and Associated Microbial Communities. Science of the Total Environment, 609, 232-241.

29. Ma, F., Lu, X., Wang, S., Wang, H., Zhao, G., 2018. Improved Process Performance of the Acidification Phase in a Two-stage Anaerobic Digestion of Complex Organic Waste: Effects of an Iron Oxide-zeolite Additive. Bioresource Technology, 262(April), 169-176.

30.Zhang, Y., Yang, Z., Xu, R., Xiang, Y., Jia, M., Hu, J., Zheng, Y., 2019. Enhanced Mesophilic Anaerobic Digestion of Waste Sludge with the Ironnanoparticles Addition and Kinetic Analysis. Science of the Total Environment, 683, 124-133.

31. Romero-Güiza, M., Zahedi, S., Monsalvo, V., Icaran, P., Pijuan, M., 2019. Nitrite and Free Nitrous Acid Sludge Pre-treatments to Enhance Methane Production in Continuous Anaerobic Digestion: Comparing Process Performance and Associated Costs. Waste Management, 95, 526-534.

32. Casals, E., Barrena, R., García, A., González, E., Delgado, L., Busquets-Fité, M., Font, X., Arbiol, J., Glatzel, P., Kvashnina, K., Sánchez, A., Puntes, V., 2014. Programmed Iron Oxide Nanoparticles Disintegration in Anaerobic Digesters Boosts Biogas Production. Small, 10(14), 2801-2808.

33. Goyal, P., Chakraborty, S., Misra, S.K., 2018. Multifunctional $\mathrm{Fe}_{3} \mathrm{O}_{4}$-Zno Nanocomposites for Environmental Remediation Applications. Environmental Nanotechnology, Monitoring and Management, 10(March), 28-35.

34. Demirel, B., Scherer, P., 2011. Trace Element Requirements of Agricultural Biogas Digesters During Biological Conversion of Renewable Biomass to Methane. Biomass and Bioenergy, 35(3), 992-998.

35. Barrena, R., Casals, E., Colón, J., Font, X., Sánchez, A., Puntes, V., 2009. Evaluation of the Ecotoxicity of Model Nanoparticles. Chemosphere, 75(7), 850-857.

36. Ateş, N., 2020. Manyetik Nanopartiküllerin Anaerobik Çürütme Performansına Etkileri, Yüksek Lisans Tezi, Fen Bilimleri Enstitüsü, Harran Üniversitesi, Şanlıurfa, 89.

37. Demir, Ö., 2018. Synthesis of $\mathrm{Fe}_{3} \mathrm{O}_{4}$ Magnetic Nanoparticles and its Applicationın Catalytic Degradation of Sulfamethoxazole in Water. J.Chem.Soc.Pak., 40(01), 111-122.

38. APHA, 2005. Standard Methods for the Examination of Water and Wastewater, $21^{\text {st }}$ Ed.; Apha: Washington, Dc, Usa, 2005. American Water Works Association/American Public Works Association/Water Environment Federation.

39. Ünşar, E.K., 2018. What Kind of Effects do $\mathrm{Fe}_{2} \mathrm{O}_{3}$ and $\mathrm{Al}_{2} \mathrm{O}_{3}$ Nanoparticles Have on Anaerobic Digestion, Inhibition or Enhancement?, 211, 726-735.

40. Zhang, Y., Jing, Y., Zhang, J., Sun, L., Quan, X., 2011. Performance of a Zv1-uasb Reactor for Azo Dye Wastewater Treatment. Journal of Chemical Technology and Biotechnology, 86(2), 199-204.

41. Gupta, V.K., Nayak, A., 2012. Cadmium Removal and Recovery from Aqueous Solutions By Novel Adsorbents Prepared from 
Orange Peel and $\mathrm{Fe}_{2} \mathrm{O}_{3}$ Nanoparticles. Chemical Engineering Journal, 180, 81-90

42. Ghaedi, M., Hajjati, S., Mahmudi, Z., Tyagi, I., Agarwal, S., Maity, A., Gupta, V.K., 2015. Modeling of Competitive Ultrasonic Assisted Removal of the Dyes-Methylene Blue and Safranin-O using $\quad \mathrm{Fe}_{3} \mathrm{O}_{4} \quad$ Nanoparticles. Chemical Engineering Journal, 268, 28-37.

43. Hattori, S., Watanabe, M., Osono, H., Togii, H., Sasaki, K., 2001. Effects of an External Magnetic Field on the Flock Size and Sedimentation of Activated Sludge. World Journal of Microbiology and Biotechnology, 17(9), 833-838.

44. Ozaki, H., Liu, Z., Terashima, Y., 1991. Utilization of Microorganisms Immobilized with Magnetic Particles for Sewage and Wastewater Treatment, in Water Science and Technology., 1125-1136.

45. Hao, W., Li, Y., Lv, J., Chen, L., Zhu, J., 2016. the Biological Effect of Metal Ions on the Granulation of Aerobic Granular Activated Sludge. Journal of Environmental Sciences (China), 44, 252-259.

46. Chen, Y., Ren, X., Gao, M., Zhao, Y., Guo, L., Shao, M., She, Z., 2018. The Influence of $\mathrm{Fe}_{2}+$, $\mathrm{Fe}_{3}+$ and Magnet Powder $\left(\mathrm{Fe}_{3} \mathrm{O}_{4}\right)$ on Aerobic Granulation and Their Mechanisms. Ecotoxicology and Environmental Safety, 164(August), 1-11.

47. Yang, Y., Zhang, C., Hu, Z., 2013. Impact of Metallic and Metal Oxide Nanoparticles on Wastewater Treatment and Anaerobic Digestion. Environmental Sciences: Processes and Impacts, 15(1), 39-48. 